\title{
ON PROPULSION DUE TO WAVY FLOW
}

\author{
M.F.PLATZER ${ }^{1} \&$ E SOROKODUM ${ }^{2}$ \\ ${ }^{1}$ AeroHydro Research \& Technology Associates, Pebble Beach, CA, USA. \\ ${ }^{2}$ Vortex Oscillation Technology Ltd, Moscow, Russia.
}

\begin{abstract}
In this paper, the effect of a wavy flow on the motion of a body in water or air is considered. Experimental results are reviewed, which show that flow waviness decreases the hydrodynamic or aerodynamic drag and even generates a forward thrust. The physics of this phenomenon is explained and examples of research vessels, dirigible balloons and unmanned air vehicles are given, which demonstrated the usefulness of this effect. The design of future vehicles is discussed to draw attention to the potential of wave propulsion for technical applications. Keywords: Katzmayr effect, oscillatory flow propulsion, unsteady aero/hydrodynamics, unsteady incompressible flows.
\end{abstract}

\section{INTRODUCTION}

Wavy air and water flow is a ubiquitous phenomenon in nature, which has many interesting facets. Here we concentrate on a phenomenon, which was first discovered in 1922 by Katzmayr [1] who published a paper in the journal Zeitschrift fuer Flugtechnik und Motorluftschiffahrt titled "Effect of periodic changes of angle of attack on behavior of airfoils." In this paper, he describes the tests he performed in the low speed wind tunnel of the Technical University of Vienna, Austria. He mounted an airfoil in the open test section while subjecting the air stream to periodic oscillations. Measurement of the lift and drag values led him to the conclusion that (his words) "the effect of flowing air, whose direction is undergoing constant periodic changes, is extraordinarily favorable on airfoils".

It is the purpose of our paper to explain the physics of the Katzmayr effect in more detail, to describe the major past attempts to exploit this effect for aircraft and ship propulsion purposes, and to draw attention to the design of future propulsion systems based on the Katzmayr effect.

\section{KATZMAYR'S EXPERIMENT}

The experiment was performed in the Eiffel-type free-jet wind tunnel of the Aero-dynamics Laboratory of the Technical University of Vienna. The flow was oscillated periodically by oscillating a number of inlet guide vanes. Three different airfoils were tested, namely a Goettingen G189, a Goettingen G413 and a LA109 airfoil, by mounting them vertically in the vertical air stream and measuring lift and drag with a mechanical balance. The airfoil chord was $150 \mathrm{~mm}$, the airfoil span $900 \mathrm{~mm}$. All the tests were made at wind speeds corresponding to a pressure of $20 \mathrm{~mm}$ of water, i.e. $196 \mathrm{~Pa}$. The frequency of oscillation of the air stream was varied from 27 to 50 oscillations/min and the amplitude could be varied to $12.5^{\circ}$. This corresponds to Strouhal numbers (based on frequency times chord divided by wind speed) of 0.005-0.0075. Figure 1 gives the measured drag polar of the G413 airfoil (reproduced from reference 1). It is seen that there is a substantial drag reduction and even a net thrust in the lower lift range compared with the airfoil in a non-oscillating flow.

\section{THE PHYSICS OF THRUST GENERATION DUE TO A TIME-VARYING} ANGLE OF ATTACK

The basic physics becomes clear by looking at Fig. 2. Whenever there is a change in angle of attack due to the wavy flow a starting vortex is shed from the trailing edge of the airfoil. Therefore, the airfoil sheds counterclockwise vorticity as long as it experiences an increase in angle of attack,

(C) 2008 WIT Press, www.witpress.com

ISSN: 1755-7437 (paper format), ISSN: 1755-7445 (online), http://journals.witpress.com

DOI: $10.2495 / D \& N E-V 3-N 2-109-120$ 


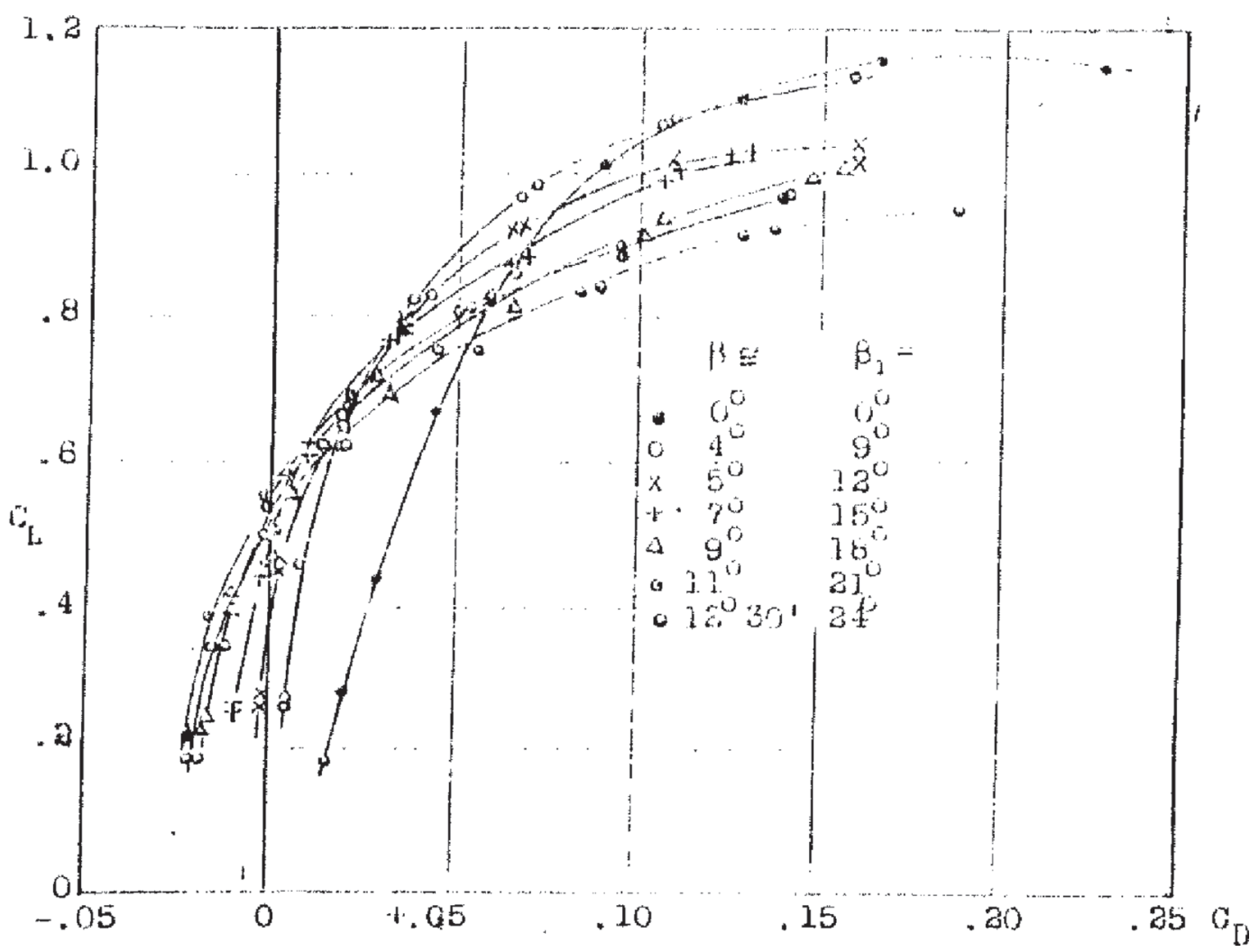

Figure 1: Drag polar of the G413 airfoil in wavy flow [1].

followed by clockwise vorticity during the period of decreasing angle of attack. As a result, a vortex street is being generated downstream of the airfoil, which induces a velocity increase between the two rows. The same phenomenon occurs if the airfoil is oscillated in a uniform flow. In Fig. 2, we show a visualization by Jones et al. [2] of the flow downstream of a NACA 0012 airfoil, which oscillates with a certain frequency and amplitude in a heave (plunge) mode. Measurements of the time-averaged velocity downstream of the trailing edge indeed yield the jet-like velocity profile shown in Fig. 2. An airfoil oscillating in a heave mode or an airfoil in an oscillatory flow therefore generates a certain amount of thrust, which depends on the frequency and amplitude of the motion or on the wavelength and amplitude of the wavy flow. Thrust generation is not limited to heave oscillations, but occurs also for pitch oscillations or combined heave and pitch oscillations. This effect has been studied quite extensively over the past few years both experimentally and computationally. The most recent information has been published by Platzer and Jones [3] and by Heathcote and Gursul [4]. Much less information is available for the case of a stationary airfoil in a wavy flow, which is the topic of our paper.

\section{SCHMIDT'S WAVE PROPELLER}

This feature of thrust generation due to wavy flow, first demonstrated by Katzmayr, appears to have attracted immediate interest. Toussaint et al. [5] in France confirmed Katzmayr's experiment in 1924 


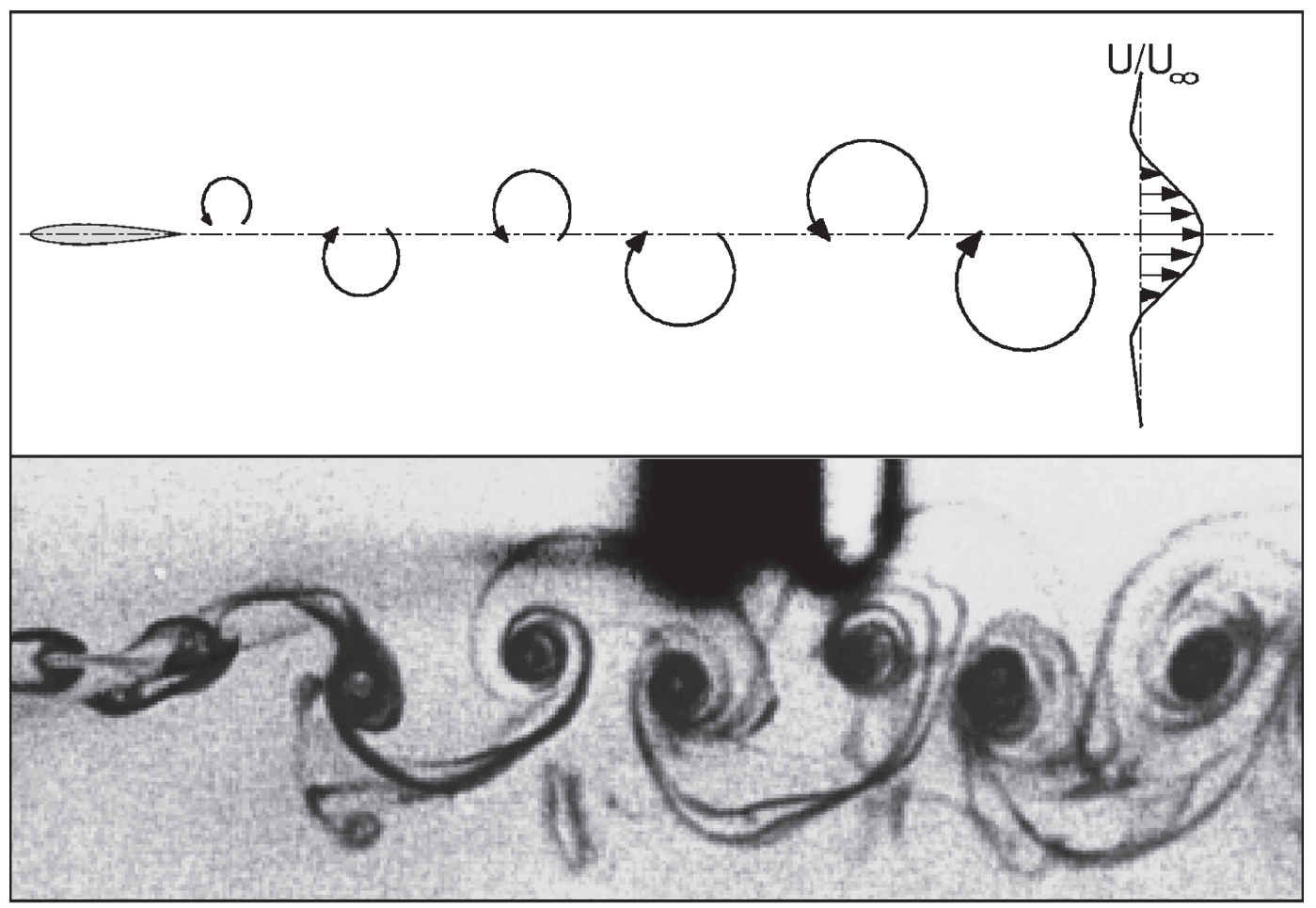

Figure 2: Vortex shedding from an airfoil oscillating in pure heave [2].

and Stamer [6] took out a German patent in the same year, wherein he proposed a tandem configuration such that the forewing was forced to flap in order to generate a wavy flow (and thrust). He argued that the stationary rear wing then generated additional thrust and thus increased the propulsive efficiency of the two wings. In 1942, Schmidt and Reichstein [7] investigated this effect in more detail. Schmidt [8,9] then proceeded to further develop this configuration, which he called wave propeller, evaluated it in wind tunnel tests, and proposed its use on catamaran boats and on air ships [10, 11]. A schematic of the wave propeller is shown in Fig. 3. The forward airfoil moves along a circle while maintaining the same incidence angle. Schmidt found this mechanism preferable to a pure up and down flapping motion because it allowed him to drive the forward airfoil at a higher frequency than possible with a pure flapping airfoil.

Schmidt [11] proposed to apply this type of wave propeller to the design of a helium-filled airship, which is capable of lifting and transporting heavy loads without changing the gas volume if it is equipped with forward, rearward and side-mounted wave propellers to give it adequate stability and maneuverability in gusty air. Figure 4 depicts the prototype built by Schmidt.

\section{EXPERIMENTAL INVESTIGATIONS OF THE WAVE PROPELLER AERO/HYDRODYNAMICS}

Schmidt performed detailed whirl arm experiments, which provided him with thrust data for his wave propeller by systematically investigating the effect of amplitude and frequency and the geometrical configuration. This information is published in references [8, 9]. 
112 M.F. Platzer \& E. Sorokodum, Int. J. of Design \& Nature and Ecodynamics. Vol. 3, No. 2 (2008)

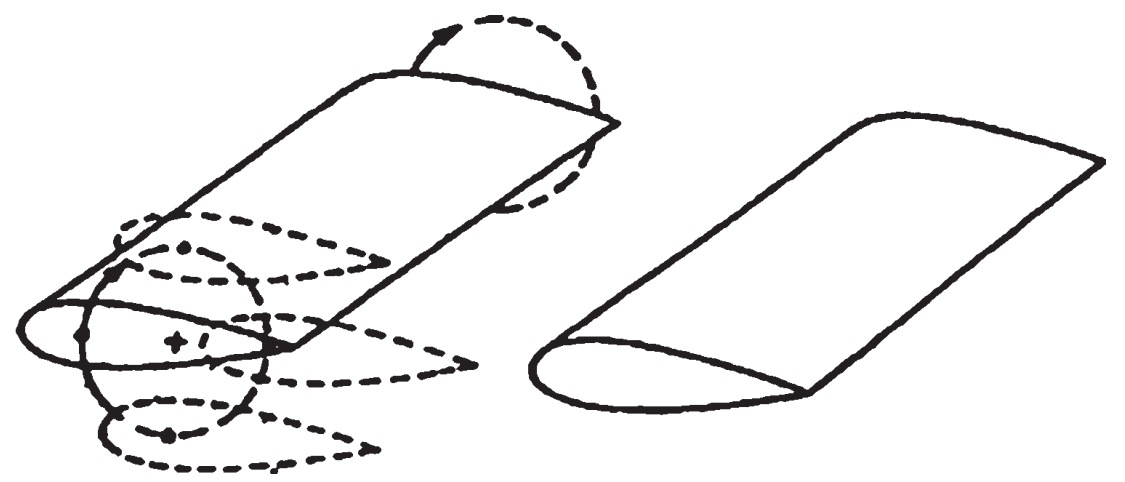

Figure 3: Schematic of Schmidt's wave propeller [10].

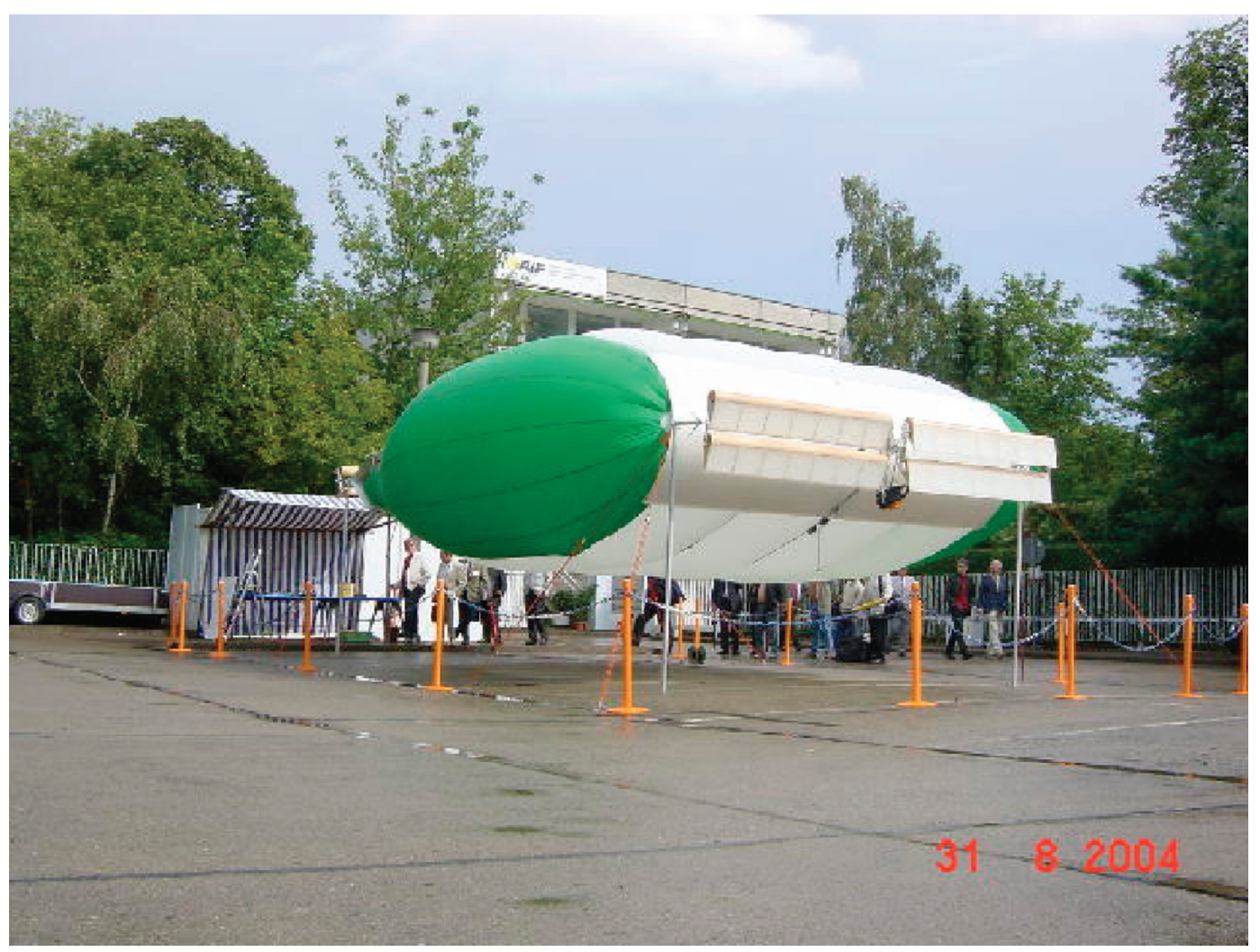

Figure 4: Schmidt's prototype of a heavy-lift airship [11]. 
More recently, Sorokodum [12] performed measurements where he generated a wavy flow by means of a sinusoidally pitching wing (NACA 0015 , chord of $0.2 \mathrm{~m}$, span of $0.37 \mathrm{~m}$ ) in front of a stationary wing held at zero incidence (NACA 0015 , chord of $1 \mathrm{~m}$, span of $0.37 \mathrm{~m}$ ). The distance between the oscillating and the stationary wing was $0.45 \mathrm{~m}$. The experiments were made in a water flow of $2.7 \mathrm{~m} / \mathrm{s}$. The amplitude of the pitching wing varied from $40^{\circ}$ at low Strouhal numbers to $20^{\circ}$ at Strouhal numbers of 0.5 and decreasing further to $9^{\circ}$ at the highest Strouhal number tested. The results are shown in Fig. 5.

The Strouhal number was used in the form of

$$
S t=\frac{f \cdot L}{U}, \quad C_{x}=\frac{2 \cdot P_{x}}{F \cdot \rho \cdot U^{2}},
$$

where $f$ is the oscillation frequency and $L$ is the wing chord length, $U$ is the flow speed, $P_{x}$ is the drag/thrust (positive values are hydrodynamic drag, negative values are thrust), $F$ is the wing area, $\rho$ is the water density. The results show the rapid decrease in drag from the steady flow value at $S t=0, f=0$, to a net thrust at Strouhal numbers from $S t=0.7$ to 2.0, corresponding to frequencies of $f=0.6-5 \mathrm{~Hz}$.

\section{COMPUTATIONAL INVESTIGATIONS OF THE WAVE PROPELLER AERO/HYDRODYNAMICS}

The first computational investigation of the interference effects between two oscillating airfoils in tandem arrangement was carried out by Bosch [13] by means of inviscid incompressible linearized flow theory. He showed that a harmonically flapping airfoil upstream of a stationary airfoil increases the propulsive efficiency to almost $100 \%$, thus confirming that the hind wing can indeed be used to convert the energy of the vortices shed from the forewing into additional thrust. Bosch's analysis is limited to flat-plate airfoils oscillating about a zero-incidence mean position. Lan [14] extended this inviscid linearized flow analysis to finite-span flat-plate wings using lifting-surface theory. $\mathrm{He}$ concluded that it is advantageous to have both tandem wings oscillating, but with appropriate phase angle between the two, to produce both high thrust and high efficiency. Platzer $e t$ al. [15] used

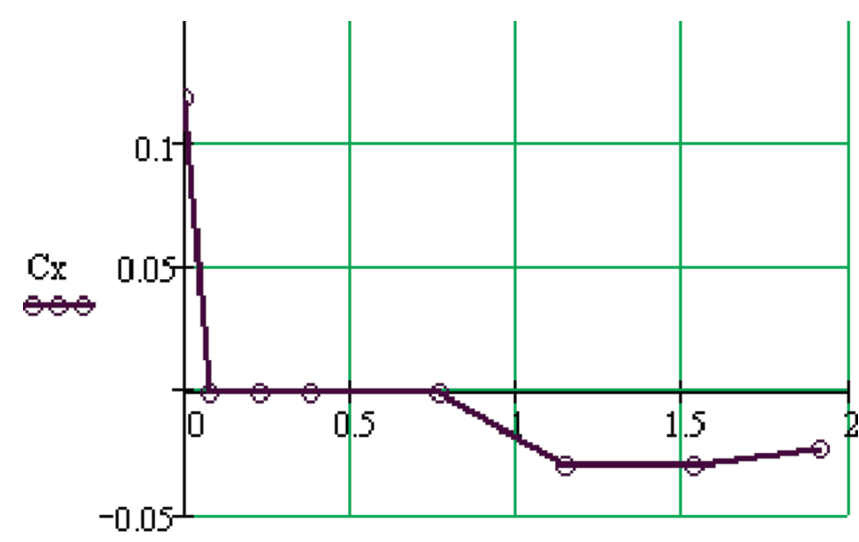

St

Figure 5: Drag/thrust coefficient $C_{x}$ vs. Strouhal number $S t$ [12]. 
a panel code to compute the incompressible inviscid flow past oscillating finite-thickness airfoils in tandem arrangement. Their results again showed good agreement with Bosch's flat-plate theory, but allowed the investigation of airfoil geometry effects. In a further panel code investigation, Jones and Platzer [16] also showed that the vortices shed from an oscillating airfoil mounted upstream of an elastically supported rear airfoil can have a substantial effect on the dynamic behavior of the rear airfoil, either exciting or suppressing flutter.

Tuncer and Platzer [17] then analyzed the effect of viscosity using a Navier-Stokes-based code. Their computations revealed the fact that viscous flow effects significantly reduce the achievable thrust and propulsive efficiency, especially in the low-frequency range. Nevertheless, they again confirmed the basic physics of the Katzmayr effect, namely that an airfoil exposed to wavy upstream flow generates a significant amount of thrust.

\section{APPLICATION OF KATZMAYR'S EFFECT ON FISH PROPULSION AND BIRD FLIGHT}

The fish is generally regarded as an efficient swimming machine. Yet, as pointed out by M.S. Triantafyllou and G.S. Triantafyllou [18], the fish tails have disappointingly low efficiency. However, a closer study shows that fish can recover energy from vortices spun off from their own bodies, which interact favorably with the tail. This phenomenon was first observed by Rosen [19] in 1959. Triantafyllou and associates [20] showed that the vortices shed from the dorsal and ventral finlets of the tuna fish can interact with the vortices generated by the tail in such a way that the body- and tail-generated vortices strengthen each other, resulting in an increased thrust, or they may interact in such a way as to decrease the strength of the total wake produced, thus increasing the propulsive efficiency. Hence, the fish is able to expose the tail to an oscillatory flow generated by the shedding of upstream vortices and thus to take advantage of the Katzmayr effect. Similarly, flapping bird wings generate an oscillatory wake, making it possible for birds flying in formation flight to take advantage of the Katzmayr effect.

\section{APPLICATION OF KATZMAYR'S EFFECT FOR SHIP PROPULSION}

As early as 1936 Pavlenko [21] seems to have been the first one to recognize the benefits to be derived from wavy water flows for ship propulsion purposes. Valuable theoretical studies of the hydromechanics of swimming propulsion were carried out by $\mathrm{Wu}$ [22] in the 1960s using linear two-dimensional theory to study the oscillations of a rigid foil moving under a free surface. Grue et al. [23] provided additional details, again using linear theory, but adding the effect of gravity. They compared their results with experiments performed by Isshiki et al. [24] and found good agreement. Two-dimensional linearized flow investigations of this problem were also performed by Kulikov et al. [25], Nikolaev et al. [26] and Konstantinov and Yakimov [27]. The latter authors showed that ship speeds up to 7 knots could be reached due to thrust generation by the oscillating wing alone.

Stefun [28] noticed already in 1959 significant ship drag reductions when he used a pair of wings as anti-rolling devices. He observed that the maximum drag reduction occurred when the length of the ship and the wavelength were approximately equal. In 1978, the first systematic ship model drag reduction tests were performed by the Norwegian company "Wave Control Company" in the Trondheim towing tank [29]. A second series of experiments were conducted by Kulikov et al. [25] in the towing tank of the Krylov Institute in Russia. They showed that a ship model with 16 rigidly mounted wings reduced the drag by $12-25 \%$ when the model executed heave-pitch and roll motions. At TSAGI in Moscow, Grebeshov and Shakarvene [30] investigated the thrust generated by a wing under a wavy free water surface, and at the Moscow State University Konstantinov and Yakimov [27] performed 
water channel experiments with a ship model, which had a pair of wings mounted at the bow. They found that the model could move forward with a speed of $0.2 \mathrm{~m} / \mathrm{s}$ in heading waves, which would correspond to a speed of 7 knots on a full-scale ship. Lai et al. [31] experimented with two yacht models, which were equipped at the stern with an elastic plate-like wing. These tests showed that the yacht models generated maximum thrust in heading waves when the ratio of the wavelength to the model length was about 1.5-2.0.

According to Rozhdestvensky and Ryzhov [32], the first tests of full-scale ships equipped with underwater flapping-wings seem to have been conducted in Russia by Grebeshov and associates in the 1970s [30,33-36]. The wings could be driven in a combined heave and pitch mode, making it possible to lift the hull out of the water and to maintain it there.

In the 1990s, Nikolaev et al. [26] tested the 174-ton research fishing vessel shown in Fig. 6. The purpose of these tests was to evaluate the wave energy extraction system mounted on the vessel's bow. The measurements showed that the engine power could be increased by up to $45-87 \%$ and reduce the ship motions by a factor of 2-2.5.

In Japan, a 20-ton trawler was equipped with a wing at the bow [37]. The tests showed that the flexibly mounted wing generated a significant amount of thrust in a certain range of wavelengths. This research vessel is shown in Fig. 7.

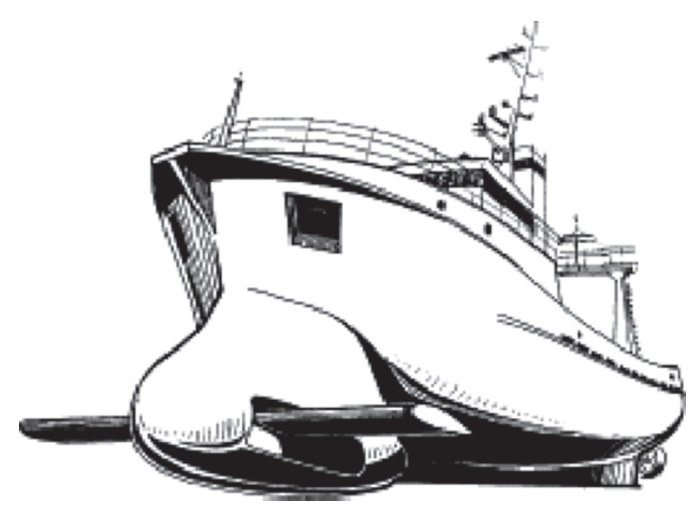

Figure 6: Russian research vessel [26].

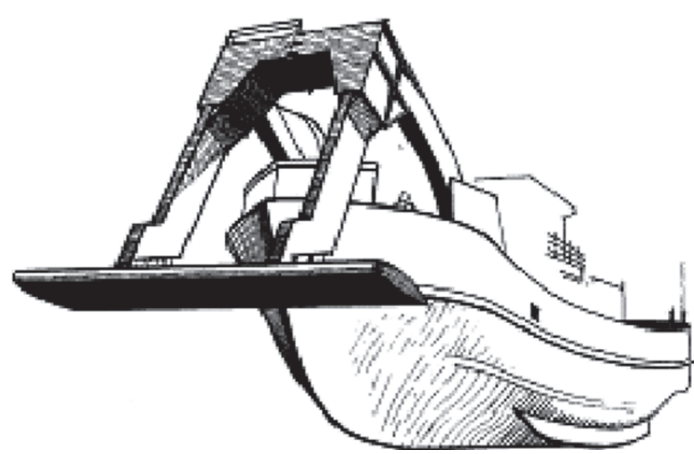

Figure 7: Japanese research vessel [37]. 
Similar tests were carried out in Norway with a 180-ton research fishing ship [38]. Two flexibly mounted wings were installed at the bow. At a speed of 15 knots in waves up to $3 \mathrm{~m}$, almost a quarter of the needed thrust was produced by the two wings and, without engine power, speeds up to 8 knots could be reached by means of the passive wing propulsors only.

\section{DESIGN CONSIDERATIONS FOR FUTURE APPLICATIONS OF WAVE PROPULSION}

The preceding review of the physics and applications of the Katzmayr effect raises the question whether its exploitation can provide advantages in the design of future marine or air vehicles.

As discussed in the previous section, the addition of rigidly or elastically mounted wings on ship hulls can lead to significant thrust increases or energy savings during operation in wavy waters provided the waves have suitable wave amplitudes and wave lengths. There does not seem to be an extensive database, which would allow the optimum design of such systems. The recent advances in computational fluid dynamics would certainly greatly facilitate the acquisition of a reliable database. Furthermore, the recent interest in the development of micro air vehicles using flapping-wing propulsion has stimulated the computational and experimental analysis of the "inverse" problem of uniform flow past flapping wings. For a summary of the current database, we refer to the papers by Platzer and Jones [3] and Heathcote and Gursul [4]. This information can be used, to some extent, to estimate the thrust and efficiency of a wing in wavy flow. Therefore, the investigation of the benefits to be derived from equipping ships with wings for operation in rough seas deserves further study. This is especially true for ships, which already use wings for stabilization purposes.

Another exploitation of the Katzmayr effect can be realized by incorporating Schmidt's wave propeller concept in the design of catamaran boats and wing-in-ground effect vehicles. Both ideas were already proposed by Schmidt in 1965 [10], but no work seems to have been done in realizing these concepts.

Figure 8 shows Schmidt's sketch of a catamaran boat with two wave propellers between the two catamaran hulls. This design appears to be still a promising configuration. Morikawa et al. [39] recently designed and tested a small boat, which was equipped with an outboard propulsor that consisted of an oscillating horizontal fin. They showed that this propulsor had a higher propulsive efficiency and afforded greater handling safety than a conventional screw propeller. They also argue that the oscillating fin propulsor is a potential environmentally friendly alternative for fishing and pleasure boats by reducing the amount of churning of the water caused by screw propellers. The use

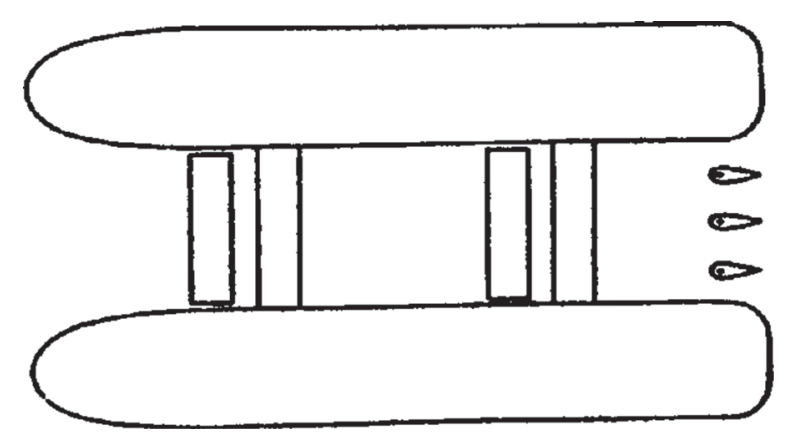

Figure 8: Schmidt's proposed catamaran boat [10]. 
of Schmidt propellers is likely to achieve even higher propulsive efficiencies because the vortices shed from the oscillating foil are converted into additional thrust by the downstream stationary foil. Schmidt's wave propeller design consisted of an oscillating foil whose attitude was held constant while the foil moved in a circle. This design has the advantage of driving the foil at a higher frequency than is possible with a plunging/pitching foil. However, it has the disadvantage that the foil will experience flow separation problems similar to the ones encountered on helicopter blades during the "retreating" part of the foil motion. Jones et al. [40] showed in their design of the flappingwing micro air vehicle (Fig. 9) that elastically mounted foils that undergo a combined plunge and pitch motion can achieve quite high thrust and efficiency levels. Also, the frequency of oscillation can be driven to rather high values with the crankshaft system developed for the micro air vehicle of Fig. 9. Furthermore, it is likely that the biplane configuration used for the micro air vehicle is preferable over a single oscillating foil because it provides a dynamically stable system. This was demonstrated quite convincingly for the micro air vehicle, which resulted in a very stable platform without any pitch oscillations of the complete vehicle. Addition of a stationary foil (or two foils) downstream of the two foils oscillating in counterphase will produce additional thrust and efficiency. While there is a considerable amount of design information available for the oscillating biplane propulsor [40], the performance characteristics of the combined biplane propulsor in combination with downstream stationary foils are still largely unexplored. The only viscous flow analysis of a single oscillating foil in combination with a downstream stationary airfoil is the one given by Tuncer and Platzer [17].

Finally, we also want to draw attention to Schmidt's proposal to use flapping-wing propulsion for the design and development of wing-in-ground effect vehicles. Schmidt's proposed configuration is shown in Fig. 10. Here, a wave propeller is mounted downstream of a large wing used to generate enough aerodynamic force to lift the vehicle out of the water and to fly it above but in close proximity to the water. It is seen from Fig. 10 that this same concept was used in the design of the micro air vehicle.

An important consideration is the speed range where flapping-foil propelled boats or wingin-ground effect vehicles might have a performance advantage. The experience and the computational

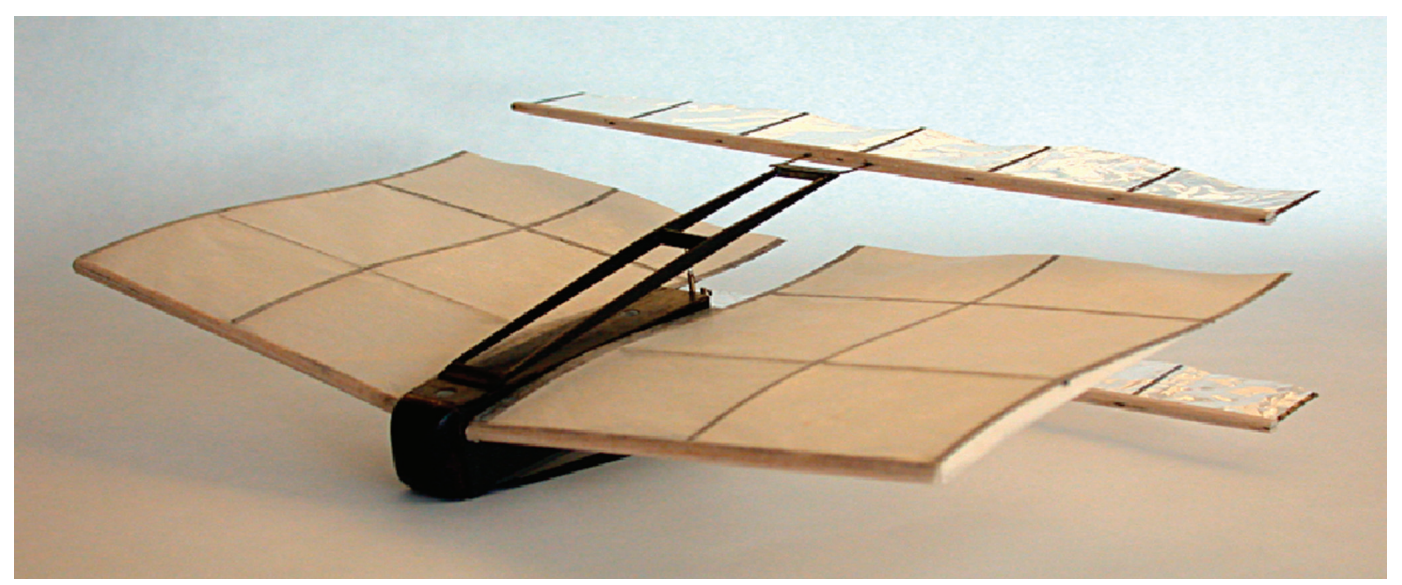

Figure 9: Micro air vehicle with elastically mounted flapping wings [40]. 


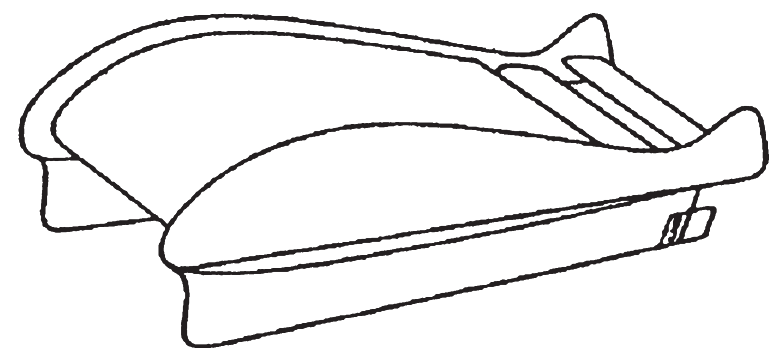

Figure 10: Schmidt's proposed wing-in-ground effect vehicle [10].

and experimental data gathered during the development of the flapping-wing propelled micro air vehicle provide some guidance. These studies revealed the importance of the Strouhal number $\mathrm{St}=f A / U$ where, $f$ is the oscillation frequency, $A$ is the amplitude of the flapping foil and $U$ is the vehicle speed. Operation at low values of the Strouhal number was found to lead to low thrust and propulsive efficiency values due to large viscous flow losses. Since the Strouhal number decreases with increasing speed this fact implies an upper limit on the vehicle speeds because there are practical limits on the achievable foil frequencies and amplitudes. Tuncer and Platzer [17] provide some information about the performance characteristics of a tandem foil arrangement where the forewing is oscillating and the hind wing is stationary on the basis of a Navier-Stokes analysis. Much more analysis and experimentation is clearly needed to provide good data for the design of flapping-wing propelled boats and wing-in-ground effect vehicles.

\section{CONCLUSION}

Thrust generation due to wavy flow is a well-established effect, which has been known for over 80 years and which has attracted considerable scientific and technical interest over the years. However, past attempts to exploit the Katzmayr effect for use on operational ships or air vehicles have not succeeded.

This situation is probably caused by the unfamiliarity of most aero/hydrodynamicists with this effect and by the reluctance to understand and analyze unsteady flow phenomena. However, the need for propulsive efficiency improvements due to the rising energy costs and the advances in computational fluid dynamics, making it easier to analyze complex unsteady flow phenomena, should stimulate renewed interest in the technical exploitation of the Katzmayr effect.

\section{REFERENCES}

[1] Katzmayr, R., Effect of periodic changes of angle of attack on behavior of airfoils, NACA TM 147, October 1922.

[2] Jones, K.D., Lund, T.C. \& Platzer, M.F., Experimental and computational investigation of flapping wing propulsion for micro air vehicles (Chapter 16). Progress in Astronautics and Aeronautics, Vol. 195, American Institute of Aeronautics and Astronautics, 2001.

[3] Platzer, M.F. \& Jones, K.D., Flapping wing aerodynamics - progress and challenges, AIAA Paper 2006-500, 2006.

[4] Heathcote, S. \& Gursul, I., Flexible flapping airfoil propulsion at low Reynolds numbers. AIAA Journal, 45(5), pp. 1066-1079, 2007. 
[5] Toussaint, Kerneis \& Girault, Experimental investigation of the effect of an oscillating air stream (Katzmayr effect) on the characteristics of airfoils, Translation from French, NACA TM 202, 1924.

[6] Stamer, F., Flugzeug mit tandemartig hintereinander angeordneten Tragflaechen, German Patent No. 458827, 27 November 1924.

[7] Schmidt, W. \& Reichstein, G., Der Knoller-Betz Effekt als Mittel zur Erhoehung des Wirkungsgrades von Schlagfluegeln. Jahrbuch 1942 der deutschen Luftfahrtforschung, pp. 432-434, 1942.

[8] Schmidt, W., Rundlaufversuche mit einem Schlagrudermodell in Luft. Deutsche Flugtechnik, Issue 11, pp. 338-341, 1959.

[9] Schmidt, W., Ueber die Abstimmung eines Schlagruderfluegels mit Nachfluegel. Deutsche Flugtechnik, Issue 11, pp. 350-352, 1960.

[10] Schmidt, W., Der Wellpropeller, ein neuer Antrieb fuer Wasser-, Land- und Luftfahrzeuge. Zeitschrift fuer Flugwissenschaften, 13(12), pp. 472-479, 1965.

[11] Schmidt, W., Delphinluftschiff mit Wellantrieb. Technischoekonomische Information der zivilen Luftfahrt, 9(4), pp. 240-243, 1973.

[12] Sorokodum, E.D., Experimental Research of a Wave Flow Wing, Unpublished Report, Sevastopol: USSR, 1988.

[13] Bosch, H., Interfering airfoils in two-dimensional unsteady incompressible flow, AGARD CP-227, Paper No. 7, September 1977.

[14] Lan, C.E., The unsteady quasi-vortex-lattice method with applications to animal propulsion. Journal of Fluid Mechanics, 93, pp. 747-765, 1979.

[15] Platzer, M.F., Neace, K.S. \& Pang, C.K., Aerodynamic analysis of flapping wing propulsion, AIAA-93-0484, January 1993.

[16] Jones, K.D. \& Platzer, M.F., Time-domain analysis of low-speed airfoil flutter. AIAA Journal, 34(5), pp. 1027-1033, 1996.

[17] Tuncer, I.H. \& Platzer, M.F., Thrust generation due to airfoil flapping. AIAA Journal, 34(2), pp. 324-331, 1996.

[18] Triantafyllou, M.S. \& Triantafyllou, G.S., An efficient swimming machine. Scientific American, pp. 64-70, March 1995.

[19] Rosen, M.W., Water Flow about a Swimming Fish, U.S. Naval Ordnance Test Station, NOTS TP 2298, 1959.

[20] Zhu, Q., Wolfgang, M.J., Yue, D.K.P. \& Triantafyllou, M.S., Three-dimensional flow structures and vorticity control in fish-like swimming. Journal of Fluid Mechanics, 468, pp. 1-28, 2002.

[21] Pavlenko, G.E., Energy extraction in the course of the ship motion in waves. Sudostroenie, 6, pp. 394-401, 1936.

[22] Wu, T.Y., Hydromechanics of swimming propulsion. Journal of Fluid Mechanics, 46, pp. 337-355, 521-568, 1971.

[23] Grue, J., Mo, A. \& Palm, E., Propulsion of a foil moving in water waves. Journal of Fluid Mechanics, 186, pp. 393-417, 1988.

[24] Isshiki, H., Murakami, M. \& Terao, Y., Utilization of wave energy into propulsion of ships - wave devouring propulsion. 15th Symposium on Naval Hydrodynamics, National Academy Press: Washington, DC, 1984.

[25] Kulikov, S.V., Kovalevsky, F.V. \& Shapovalova, N.A., Application of a hydrofoil system as passive energy saving means for ship advancing in seas. 17th SMSHH' 88 , Scientific and Methodological Seminar on Ship Hydrodynamics, Vol. 2, Varna, Bulgaria, pp. 48.1-48.6, 1988. 
120 M.F. Platzer \& E. Sorokodum, Int. J. of Design \& Nature and Ecodynamics. Vol. 3, No. 2 (2008)

[26] Nikolaev, M.N., Savitskiy, A.I. \& Senkin, Y.U.F., Basics of calculation of the efficiency of a ship wave propulsor of the wing type. Sudostroenie, Issue 4, pp. 33-41, 1995.

[27] Konstantinov, G.A. \& Yakimov, Y.L., Calculation of thrust of the ship propeller, utilizing the energy of sea waves, Izvestia AN Rossii. Mekhanika Zhidkosti I Gaza, Issue 3, pp. 139-143, 1995.

[28] Stefun, G.P., Model experiments with fixed bow antipitching fins. Journal of Ship Research, 3(2), pp. 36-43, 1959.

[29] Wave energy propulsion. Norwegian Shipping News, 40(16), p. 50, 1984.

[30] Grebeshov, E.P. \& Shakarvene, E.K., On the problem of use of the energy of sea waves. Sbornik trudov NTO sudostroitelnoi promyshlennosti im Akad AN Krylova: Gidrodynamika krylievykh dvizhielno-rulevykh kompksov, Vol. 512, pp. 15-31, 1992.

[31] Lai, P.S.K., Bose, N. \& McGregor, R.C., Wave propulsion from a flexible-armed, rigid-foil propulsor. Maritime Technology, 30(1), pp. 28-36, 1993.

[32] Rozhdestvensky, K.V. \& Ryzhov, V.A., Aerohydrodynamics of flapping-wing propulsors. Progress in Aerospace Sciences, 39, pp. 585-633, 2003.

[33] Grebeshov, E.P. \& Kovryshnykh L.D., Propulsive characteristics of a wing propulsor operating near ground surfaces. Trudy TSAGI, 2211, pp. 6-20, 1983.

[34] Grebeshov, E.P. \& Ruchin, A.P., Some matters of hydrodynamics of a propulsor of the flapping wing type. Trudy TSAGI, 2380, pp. 1-24, 1988.

[35] Grebeshov, E.P. \& Sagoyan, O.A., Hydrodynamic characteristics of oscillating wing, performing function of a lifting element and a propulsor. Trudy TSAGI, 1725, pp. 3-30, 1976.

[36] Grebeshov, E.P. \& Shakarvene, E.P., On the question of drag of a wing in unsteady flow regime. Gidrodynamika bolshikh skorostei, Trudy 3 Vsesouznoi shkoly seminara, Kranoyarsk, pp. 175-183, 1987.

[37] Bulletin of the Society of Naval Architects of Japan, No. 719, pp. 18-26, 1989.

[38] Klart for Utproving av Foilpropellen. FisketsGang, 18, pp. 526-527, 1987.

[39] Morikawa, H., Hiraki, A., Kobayashi, S. \& Muguruma, Y., Outboard Propulsor with an Oscillating Horizontal Fin. Bio-mechanisms of Swimming and Flying, eds N. Kato, J. Ayers \& H. Morikawa, Springer-Verlag: Tokyo, pp. 67-78, 2004.

[40] Jones, K.D., Bradshaw, C.J., Papadopoulos, J. \& Platzer, M.F., Bio-inspired design of flapping-wing micro air vehicles. The Aeronautical Journal, 109(1098), pp. 385-393, 2005. 